\title{
SOME NOTES ON RELATION BETWEEN INTERMEDIATE METABOLISM AND THE CHANGE OF BODY- WEIGHT OF RATS EXERCISED BY RUNNIG OF 8 WEEKS
}

\author{
Keizo Kobayashi*, Koji Hashizume* and Suketsune Iwagaki*
}

In physical exercise of long period, change of body weights are usually used as an effect on the living body influenced from the work load. We have carried out the experiments studying a relationship between work intensity of the physical exercise and the intermediate metabolism of rats runned by means of the treadmill. In the process of these experiments, we have met with unexpected phenomena showing sudden death and extreme decrease of body weight.

In order to examine the reason of these phenomena as mentioned above, the biochemical analysis of organs and tissues in the rats which the physical exercise of 8 weeks loaded by the treadmill was carried out. (Fig. 1)

After sacrificing the test rat, glycogen, triglyceride, FFA and phospholipids in muscles (myocardial muscle, gastrocnemius muscle, tibialis anterior muscle and diaphragm muscle) and liver, and GOT, GPT, Al-P, LDH and lipids in serum were measured. These substrates mentioned above were determined by the method as follows: glycogen by GoodKramer and Somgyi's method ${ }^{7)}$, triglyceride by the Stren and Shapiro's method $^{9)}$, FFA by the Duncombe's method ${ }^{3)}$, cholesterol by the Abell, Levy, Bordie and Kendall's method, phospholipids by the Bartllett's method ${ }^{2}$, GOT and GPT by the Reitman and Frankel's

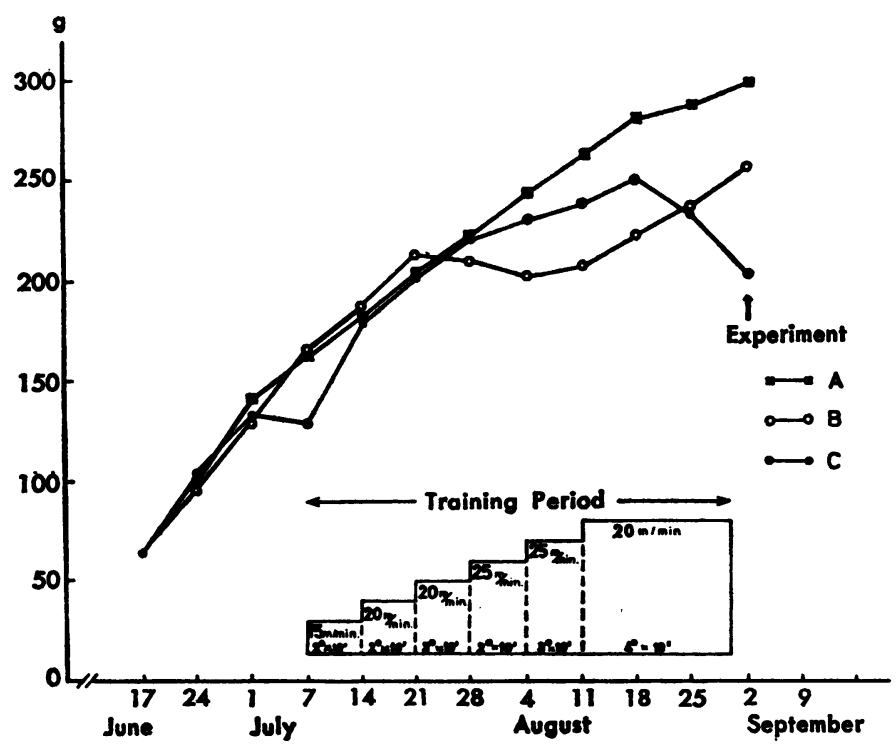

Fig. 1 Body growth curves of sedentary and exercised rats. Rats were fed under the same condition for first 3 weeks and rats were loaded with the treadmill graded running for 8 weeks. At the end of exercise period rats were classified into three types from their body growth curves : sedentary $\operatorname{rat}(A)$, exercised $\operatorname{rat}(B)$ and excercised $\operatorname{rat}(C)$.

* Department of physiology, The Jikei University School of Medicine 
method $^{8)}$, Al-P by the Bessey, Lowry and Brock's method ${ }^{8)}$, and LDH by the Caubaud and Wroblewski's method.) Lipids extraction from tissue and serum was done by the Folch, Lees and Sloanestanley's method ${ }^{6)}$ and each lipids was separated by TLC method: neutral lipids by solvent (petroleum ether/diethyl ether/acetic acid, $90: 10: 1 \mathrm{v} / \mathrm{v} / \mathrm{v}$ ) and phospholipds by the solvent (chrolofolm/methanol/28\% ammonium hydroxide, 14:6:1 $\mathrm{v} / \mathrm{v} / \mathrm{v})$.

Changes of the body weight of the rats during exercise are presented in Fig. 1 . For first week, rats were runned 6 days per week by means of the treadmill inclined $2^{\circ}$ for 10 minutes at the speed of $15 \mathrm{~m} / \mathrm{min}$. After this exercise, work load was gradually strengthened by increasing of running speed and inclination of the treadmill, as indicated in Fig. 1.

Individual differences among their body weights were appeared by the exercise for 4 weeks, and apparent differences were distinguished by the exercise for 8 weeks.

Sedentary rat (A) showed normal growth curve in body weight. That of exercised rat(B) decreased on the middle of exercise-period, but increased on the end of this period. Body weight of the rat (B) was lower than that of rat (A). That of exercised rat (C) began to decrease abruptly at the end of exercise-period. The body weight of the each group at the final period of exercise become to weight of (A), (B) and (C) in that order.

The measured substrates in tissues and serum mentioned above were presented in Fig. 2, 3 and 4. Glycogen level in myocardial muscle and liver and FFA level in myocardial muscle of exercised $\operatorname{rat}(B)$ were higher than those of sedentary rat (A), while in exercised rat(C), levels of triglyceride, total phospholipids, and phosphatidylethanolamine in serum and triglyceride in gastrocnemius muscle showed the lowest values. Substrates which show. ed paralellism in change of their body weights (A,B and C in that order) were triglyceride in liver and gastrocnemius muscle (Fig. 2), FFA in gastrocnemius muscle and cholesterol,

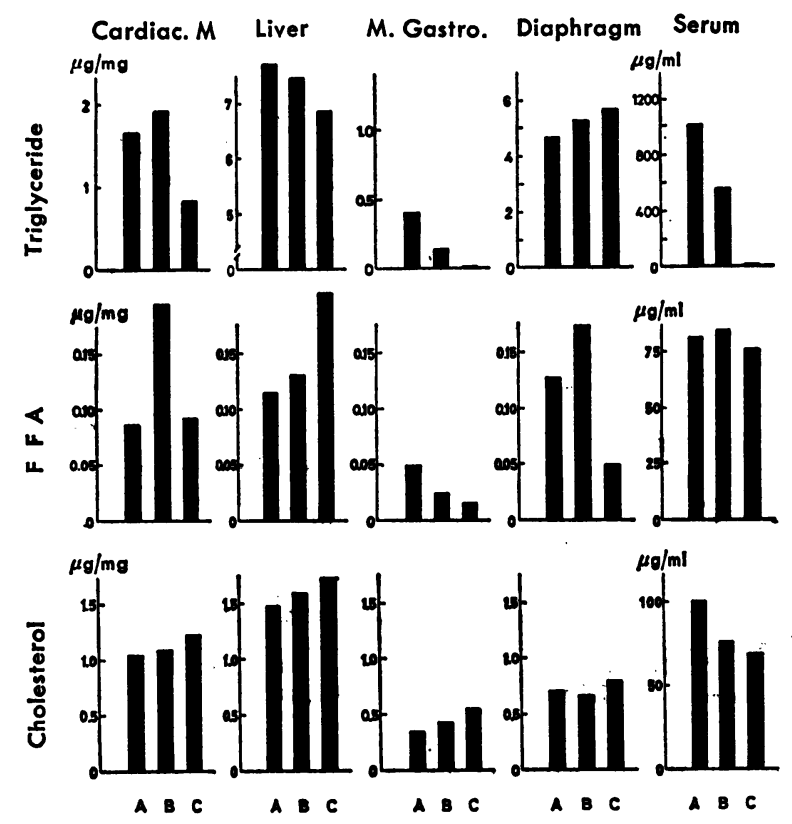

Fig. 2 Triglyceride, free fatty acids and cholesterol in cardiac muscle, gastrocnemius muscle, diaphragm muscle, liver and serum of each rats. The content was expressed as $\mu \mathrm{g}$ per wet tissue weight $(\mathrm{mg})$ and the concentration was expressed as $\mu \mathrm{g}$ per $\mathrm{ml}$. 


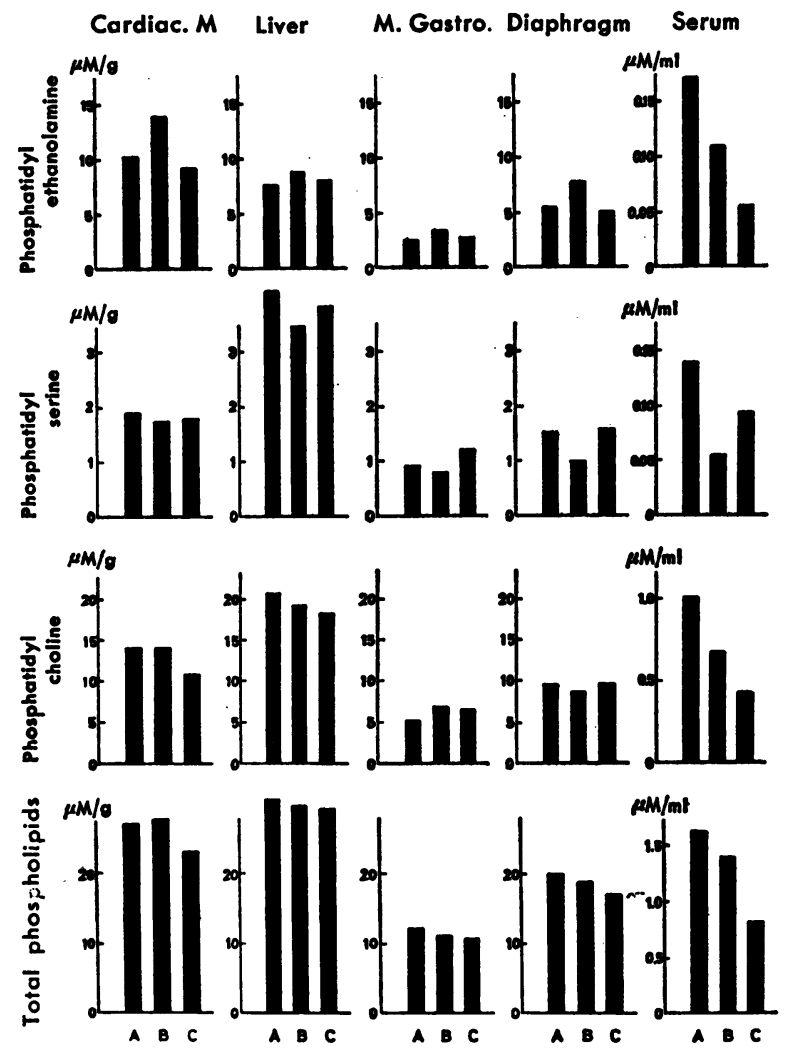

Fig. 3 Total phospholipids, phosphatidylcholine, phosphatidylserine and phosphatidylethanolamine contents in cardiac muscle, gastrocnemius muscle, diaphragm muscle, serum and liver of each rats. The content was expressed as $\mu \mathrm{M}$ per wet tissue weight (g).

Cardiac. M Liver M. Gastro. M. Tib.Ant.

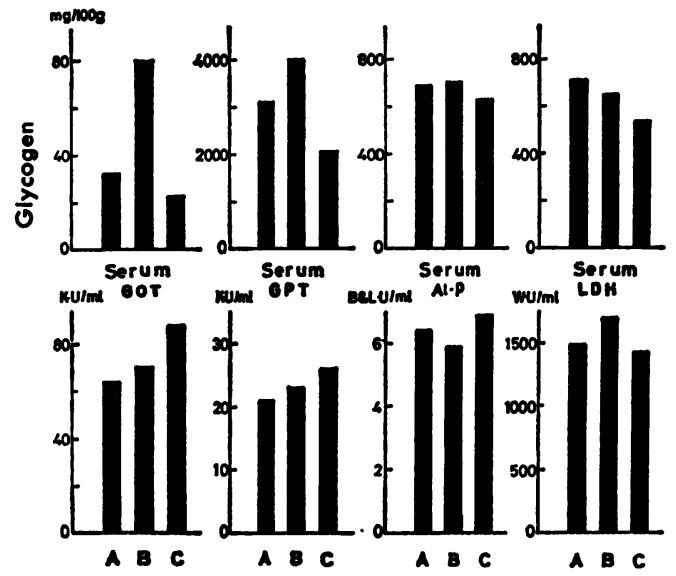

Fig. 4 Glycogen content in cardiac muscle, gastrocnemius muscle, diaphragm muscle and liver, and concentration of GOT, GPT, Al-P and LDH in serum of each rats. Glycogen content was expressed as $\mathrm{mg}$ per $100 \mathrm{~g}$ wet tissue weight. GOT, GPT, Al-P and LDH were expressed as units per $\mathrm{ml}$. 
triglyceride, total phospholipids, phosphatidylethanolamine and phosphatidylcholine in serum (Fig. 2, 3). On the contrary, substrates which showed a reverse tendency against change of their body weights were liver FFA (Fig. 2) and serum GOT (Fig. 4). These biochemical changes suggest cellular dysfunction of liver, which would be caused by the exercise of long period. Serum lipids decreased in the rat (C) were almost contained in lipoproteins which released from liver, and decrease of these lipids was thought to reflect the dysfunction of liver. Relation between increase of FFA and decrease of triglyceride in liver shows restrained synthesis of triglyceride. And increase of serum GOT also suggests metabolic dysfunction of liver indirectly.

Then, it is considered that in the exercise for long period, work load and its repetition fitted to the change of individual body weights should be used, especially on the case of remarkable decrease of body weight.

The authors wish to thank Prof. Toshio Sakai, of Dept. of Physiology. The Jikei University School of Medicine for his valuable discussion and comments.

(Received for publication July 4, 1975)

\section{References}

1) Abell, L.L., Leby, B.A., Brodie, B.B. and Kendall, F.F. : A simplified method for the estimation of total cholesterol in serum and demonstration of its specificity. J. Biol. Ciem., 195 : 357-366, 1925.

2) Bartlett, G.R. : Phosphorus assey in colum chromatography. J. Biol. Chem., 234 : 466-468, 1959.

3) Bessey, O.A., Lowry, O.H., and Brock, M.J. : A method for the rapid determination of alkaline phosphatase with five cubic millimeters of serum. J. Biol. Chem. $164: 321-329,1964$.

4) Cabaud, P.G., Wroblewski, F. : Colorimetric measurement of lactic dehydrogenase activity of body fluids. Am. J. Clin. Path., 30 : 234-236, 1958.

5) Duncombe, W.G. : The colorimetric microdetermination of long-chain fatty acids. Biochem. J., 88 (7) : 7-10, 1963.

6) Folch, J., Lees, M. and Sloanestanley, G.H. : A simple method for the isolation and purification of total lipids from animal tissue. J. Biol. Chem., $226: 497-509,1957$.

7) Good, C.A., Kramer, H., and Somogyi, M. : The determination of glycogen. J. Biol. Chem., 100: 485-495, 1933.

8) Reitman, S. and Frankel, S. : A colorimetric method for the determination of serum glutamic oxalatic and glutamic-pyruvic transaminase. Am. J. Clin. Path., $28: 56-63,1957$.

9) Stern, I. and Shapiro, B. : A rapid and simple method for determination of esterified fatty acid and for total fatty acid in blood. J. Clin. Path., $6: 158-160,1963$. 